Optimalisasi Sumber Daya Alam Matra Darat dan Matra Lautan untuk Ketahanan Pangan dan Kesehatan dalam Konteks Nasionalisme

\title{
ANALISIS POTENSI PEREKONOMIAN SEKTOR PERTANIAN, KEHUTANAN, DAN PERIKANAN SERTA PERTAMBANGAN DAN PENGGALIAN DI PANTURA JAWA BARAT
}

\author{
Moh. Dede ${ }^{1}$, Rizal Sahidin Banyu Sewu² , Meisa Yutika³ ${ }^{3}$ Fatich Ramadhan ${ }^{4}$ \\ ${ }^{1}$ Pendidikan Geografi, Universitas Pendidikan Indonesia \\ Jalan Dr. Setiabudhi No.229 Bandung 40254, m.dede.geo@gmail.com \\ ${ }^{2}$ IImu Ekonomi dan Studi Pembangunan, Universitas Padjadjaran \\ Jalan Dipati Ukur No. 35 Bandung 40132, jovanadriandavion@gmail.com \\ ${ }^{3}$ Hukum Ekonomi Syariah, Universitas Islam Negeri Sunan Gunung Djati \\ Jalan A.H. Nasution No.105 Bandung 40614, meisa.eca8@gmail.com \\ ${ }^{4}$ Pendidikan Geografi, Universitas Pendidikan Indonesia \\ Jalan Dr. Setiabudhi No.229 Bandung 40254, fatich35@gmail.com
}

\begin{abstract}
ABSTRAK
Kekayaan sumber daya alam di Indonesia begitu melimpah, baik di darat maupun perairan yang menjadi penggerak ekonomi di tingkat daerah hingga nasional. Salah satu provinsi yang menyumbang produk domestik regional bruto (PDRB) terbanyak adalah Jawa Barat (14,17 persen). Sebanyak 33,88 persen PDRB Jawa Barat berasal dari wilayah pantura yang terdiri atas Kabupaten Bekasi, Kabupaten Cirebon, Kabupaten Indramayu, Kabupaten Karawang, Kabupaten Subang, dan Kota Cirebon. Pantura Jawa Barat dikenal sebagai wilayah sentra pertanian, kehutanan, dan perikanan serta pertambangan dan penggalian. Penelitian ini bertujuan untuk mengetahui potensi optimalisasi berbagai sektor yang bertumpu pada sumber daya alam darat dan perairan di Pantura Jawa Barat. Metode penelitian yang digunakan adalah ex post facto dengan menggunakan data dari Badan Pusat Statistik (BPS) tahun 2011 hingga 2015 yang dianalisis menggunakan 'multiplier effect' model Tiebout (dengan 'Locational Quotient' atau LQ), Model Rasio Pertumbuhan (MRP) yang terdiri atas Rasio Pertumbuhan Wilayah Studi (RPs) dan Rasio Pertumbuhan Wilayah Referensi (RPr), dan analisis 'overlay'. Berdasarkan analisis ini diketahui bahwa pemanfaatan sumber daya darat dan perairan di berbagai sektor yang tercermin dari pertambangan dan penggalian sebagai sektor unggulan di Pantura Jawa Barat dengan nilai multiplier effect (LQ), RPs, dan RPr selama lima tahun sebesar 22,50 (1,87), 1,40, dan -0,15. Hal ini berarti sektor pertambangan dan penggalian merupakan spesialisasi ekonomi di Pantura Jawa Barat. Melalui penelitian ini diharapkan memberikan pemahaman bagi pemerintah dan masyarakat dalam rangka optimalisasi pemanfataan sumber daya alam darat dan perairan guna menggairahkan marwah pembangunan yang berkelanjutan.
\end{abstract}

Kata Kunci: analisis overlay, LQ, multiplier effect, MRP, Pantura Jawa Barat

\section{A. PENDAHULUAN}

Indonesia merupakan negara yang kaya akan sumber daya alam, baik yang tersebar di darat (terestrial) maupun di perairan (akuatis). Keberadaan sumber daya alam darat dan perairan dalam perekomian nasional secara langsung tergambar pada sumbangan sektor pertanian, kehutananan, dan pertambangan serta sektor pertambangan dan penggalian terhadap Produk Domestik Bruto (PDB) atau Gross National Product (GNP) dengan rata-rata tahunan sebesar 23,16 persen dalam rentang tahun 2011 s.d. 2015 (BPS, 2015 hlm. 67-70). Hal ini menjadikan kekayaan sumber daya alam terestrial dan akuatis di Indonesia berpotensi sebagai pasar investasi baru di dunia selain Brazil, Peru, Rusia, dan Afrika Selatan yang sering disebut sebagai Commodity-Rich Countries dengan pangsa pasar 
Indonesia yang terdiri atas bahan baku (10 persen) dan energi (17 persen) (S\&P Global Division, 2011 hlm. 16-20; David, 2011; Sauter, dkk., 2012).

Produk Domestik Bruto (PDB) di suatu negara merupakan hasil gabungan dari berbagai produk domestik bruto pada tingkat regional yang dikenal sebagai Produk Domestik Regional Bruto (BPS Jawa Barat, $2016 \mathrm{hlm}$. 1). Salah satu provinsi yang menyumbang produk domestik regional bruto (PDRB) terbanyak yaitu 14,17 persen bagi PDB Nasional pada tahun 2013 dengan presentase sektor pertanian, kehutanan, dan perikanan serta sektor pertambangan dan penggalian sebesar 10,25 persen (Kementerian Koordinator Bidang Perekonomian Republik Indonesia, 2013). Di Jawa Barat sendiri, terdapat kawasan Pantura Jawa Barat yang menyumbangkan 33,88 persen nilai PDRB. Kenyataannya, Hanya sekitar 12 persen PDRB Pantura Jawa Barat berasal dari sektor primer, seperti pertanian, kehutanan, perikanan, pertambangan, dan penggalian, padahal lebih dari 30 persen wilayahnya merupakan lahan yang dimanfaatkan pada sektor-sektor tersebut (BPS Kabupaten Bekasi, 2016 hlm. 92; BPS Kabupaten Cirebon, 2016 hlm. 92; BPS Kabupaten Indramayu, 2016 hlm. 67; BPS Kabupaten Subang, 2016 hlm. 61; BPS Kota Cirebon, 2016 hlm. 72). Secara geografis, Pantura Jawa Barat memiliki potensi pertanian dan perikanan yang tinggi sebagai wilayah dataran rendah dan pesisir bila dibandingkan dengan wilayah yang memiliki corak pegunungan (Sultani, $2016 \mathrm{hlm}$. 14).

Oleh karena itu, penentuan pengembangan berbagai sektor unggulan di suatu wilayah baik bersifat regional maupun nasional dalam rangka awal optimalisasi pembangunan harus dilakukan. Hal ini diharapkan agar sesuai dengan misi Provinsi Jawa Barat yang tertuang dalam Rencana Pembangunan Jangka Menengah Daeerah Tahun 2013-2018 yaitu membangun perkonomian serta meningkatnya pembangunan ekonomi regional di Jawa Barat dapat terwujud dengan baik (Pemprov Jawa Barat, $2013 \mathrm{hlm}$. V-3).

Atas dasar hal tersebut, tujuan penelitian pada artikel ini dimaksudkan untuk mengetahui potensi optimalisasi berbagai sektor ekonomi yang bertumpu pada sumber daya alam darat dan perairan di Pantura Jawa Barat. Dengan lingkup bahwa berbagai macam pemanfaatan sumber daya alam darat dan perairan di berbagai sektor tercermin di sektor pertanian, kehutanan, dan perikanan serta sektor pertambangan dan penggalian yang didasarkan pada nilai pendapatan pada masingmasing sektor yang memberikan sumbangsih berarti terhadap perekenonomian (Raven, Hassenzahl, dan Berg, 2013 hlm. 30).

\section{B. METODE PENELITIAN}

Penelitian ini menggunakan data PDRB dari Badan Pusat Statistik (BPS) tahun 2011 hingga 2015 meliputi Kabupaten Bekasi, Kabupaten Cirebon, Kabupaten Indramayu, Kabupaten Karawang, Kabupaten Subang, Kota Cirebon, dan Provinsi Jawa Barat yang kemudian dianalisis menggunakan multiplier effect model Tiebout, Locational Quotien atau LQ, Model Rasio Pertumbuhan (MRP) yang terdiri atas Rasio Pertumbuhan Wilayah Studi (RPs) dan Rasio Pertumbuhan Wilayah Referensi (RPr), dan analisis overlay yang kemudian diinterpretasikan oleh penulis. Metode penelitian yang digunakan adalah ex post facto mempergunakan data PDB dan PDRB dengan nilai harga konstan, karena nilai harga konstan mampu menunjukan laju pertumbuhan ekonomi secara riil dan menyeluruh pada setiap sektor dari tahun ke tahun tanpa terpengaruh oleh inflasi (BPS Jawa Barat, $2016 \mathrm{hlm}$. 2). Selain itu, pemilihan penggunaan data pendapatan (PDRB) merupakan pilihan terbaik bila didandingkan dengan data tenaga kerja. Hal ini terjadi karena bobot dan distribusi tenaga kerja berbeda-beda dan dipengaruhi oleh SDM (Tarigan, $2015 \mathrm{hlm} .31$ ). 


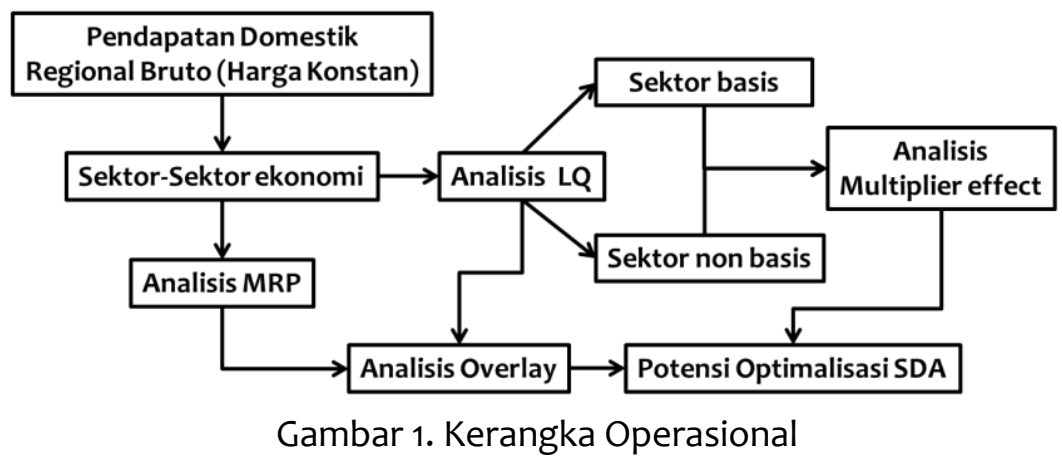

\section{TINJAUAN TEORITIS}

\section{Multiplier Effect dan Locational Quotient}

Dalam teori basis ekonomi, perkembangan suatu wilayah ditentukan oleh besarnya permintaan ekspor (demand) oleh sektor basis (Tarigan, 2015 hlm. 28; Mankiw, 2012 hlm. 556). Sedangkan sektor non basis merupakan sektor yang mencukupi kebutuhan internal wilayah tersebut saja atau subsisten (Dicken dan Lloyd, $1990 \mathrm{hlm}$. 390).

Penentuan kemampuan tiap sektor ekonomi (basis dan non basis) dapat menggunakan locational quotient (LQ) sebagai sebagai langkah awal untuk memahami sektor basis disuatu wilayah sebagai pemacu pertumbuhan (Gantara dan Achamadi, $2012 \mathrm{hlm}$. 1). Sedangkan, multiplier effect atau pengganda basis didasarkan pada hubungan berbagai sektor pembentuk ekonomi yang saling terkait serta memiliki ketergantungan dalam ekonomi di suatu wilayah. Sehingga, setiap perubahan pada sektor basis sebagai salah satu sektor pembentuk ekonomi, akan mempengaruhi perubahan struktur ekonomi secara keseluruhan di suatu wilyah (Manacika, 2010 hlm. 11; Sukma 2015 hlm. 104).

Perhitungan multiplier effect dan locational quotient dapat dilakukan dengan menggunakan data pendapatan atau ketenagakerjaan, baik dalam bentuk tunggal maupun data berseri (data series).

\section{a. Menentukan Sektor Basis dan Non Basis dengan LQ}

$$
L Q=\frac{\frac{P D R B \text { Sektor } i \text { tingkat Kab./Kota/Kawasan }}{\text { PDRB Total tingkat Kab./Kota/Kawasan }}}{\frac{\text { PDRB Sektor } \text { i tingkat Provinsi }}{\text { PDRB Total tingkat Provinsi }}}
$$

Dengan ketentuan, jika nilai LQ $>1$ maka sektor tersebut merupakan sektor basis, tetapi apabila nilai LQ $\leq 1$ disebut sebagai sektor non basis (Tarigan, 2015 hlm. 35; Muta'ali, 2015 hlm. 95).

\section{b. Menentukan Nilai Pengganda Basis (PB)}

$$
\mathrm{PB}=\frac{Y_{\text {total }}}{Y_{\text {basis }}}=\frac{1}{1-\frac{Y \text { non basis }}{Y \text { total }}}
$$

Nilai pengganda basis yang tinggi diinterpretasikan sebagai kemampuan kinerja sektor basis dalam menunjang kinerja sektor non basis yang menyebabkan pertumbuhan dan pembangunan wilayah menjadi tinggi. Nilai pengganda basis ditentukan oleh $Y_{\text {Total }}$ merupakan PDRB Total, $\mathrm{Y}_{\text {Basis }}$ merupakan pendapatan sektor basis, $\mathrm{Y}_{\text {non basis }}$ merupakan pendapatan sektor non basis, dan LQ adalah Locational Quotient 


\section{Analisis Model Rasio Pertumbuhan (MRP)}

Analisis Model Rasio Pertumbuhan (MRP) Analisis MRP merupakan alat analisis untuk melihat deskripsi kegiatan atau sektor ekonomi yang potensial berdasarkan pada kriteria pertumbuhan struktur ekonomi wilayah baik eksternal maupun internal (Nisa, $2014 \mathrm{hlm}$. 55). Analisis MRP ini dibagi lagi ke dalam dua kriteria, yaitu Rasio Pertumbuhan Wilayah Studi (RPs) dan Rasio Pertumbuhan Wilayah Referensi (RPr). Berikut ini penjelasan beberapa kriteria dalam analisis MRP.

a. Rasio pertumbuhan wilayah studi (RPs) yaitu perbandingan antara pertumbuhan pendapatan.

Dalam hal ini ialah pertumbuhan PDRB sektor i di wilayah kajian dengan pertumbuhan pendapatan PDRB sektor i di wilayah referensi (kabupaten/kota/kawasan terhadap Provinsi).

$$
R P s=\frac{\Delta \mathrm{Eij} / \mathrm{Ei}}{\Delta \mathrm{Ein} / \mathrm{Ein}}
$$

Keterangan :

$\Delta \mathrm{E}_{\mathrm{ij}} \quad=$ Perubahan PDRB sektor i di wilayah

$\mathrm{E}_{\mathrm{ij}} \quad=$ PDRB sektor $\mathrm{i}$ di wilayah $\mathrm{j}$ pada awal tahun penelitian

$\Delta \mathrm{E}_{\text {in }} \quad=$ Perubahan PDRB sektor i secara nasional/provinsi

$\mathrm{E}_{\text {in }} \quad=$ PDRB sektor i secara nasional/provinsi pada awal tahun penelitian

Jika RPs lebih besar dari 1 maka RPs dikatakan (+), berarti pertumbuhan suatu sektor produksi tertentu di tingkat kabupaten atau kota lebih tinggi dari pertumbuhan sektor produksi tertentu provinsi dan jika RPs lebih kecil dari 1 dikatakan (-), berarti pertumbuhan suatu sektor produksi tertentu di tingkat kabupaten/kota/kawasan lebih rendah dari pertumbuhan sektor provinsi (Sabar, 2015 hlm. 54).

b. Rasio pertumbuhan wilayah referensi (RPr) yaitu perbandingan antara laju pertumbuhan pendapatan kegiatan i di wilayah referensi dengan laju pertumbuhan total kegiatan (PDRB) wilayah referensi (Provinsi).

Keterangan:

$$
R P r=\frac{\Delta \text { Ein } / \text { Ein }}{\Delta \text { En } / \text { En }}
$$

$\Delta$ Ein $\quad=$ Perubahan PDRB sektor i secara nasional/provinsi

Ein $=$ PDRB sektor i secara nasional/provinsi pada awal tahun penelitian

$\Delta \mathrm{En} \quad=$ Perubahan PDRB nasional/provinsi

En $\quad=$ Total PDRB nasional/Provinsi pada awal tahun penelitian

Jika nilai RPr $>1$ diberi notasi positif $(+)$ yang menunjukkan pertumbuhan suatu sektor tertentu dalam wilayah referensi (provinsi/nasional) lebih tinggi dari pertumbuhan PDRB total wilayahnya, sedangkan nilai $\mathrm{RPr}<1$ diberi notasi negatif (-) yang menunjukkan pertumbuhan suatu sektor tertentu dalam wilayah referensi (provinsi/nasional) lebih rendah dari pertumbuhan PDRB total wilayahnya (Putra, $2013 \mathrm{hlm}$. 37).

\section{Analisis Overlay}

Analisis Overlay digunakan untuk menentukan sektor unggulan dengan menggabungkan alat analisis untuk menyaring hasil analisis yang paling baik. Nilai positif (+) merupakan sektor unggulan dan begitu juga sebaliknya (Sabar, $2015 \mathrm{hlm}$. 54). Notasi positif berarti koefisien komponen lebih dari satu dan negatif kurang dari satu.

Terdapat tiga kriteria dalam analisis overlay (Sabar, $2015 \mathrm{hlm}$. 54-55), yaitu :

a. RPr, RPs, dan LQ ketiganya bernilai positif (+), berarti sektor tersebut mempunyai potensi daya saing kompetitif maupun komparatif yang lebih unggul dibanding sektor yang sama di tingkat provinsi. 
b. RPr bernilai negatif (-), sedangkan RPs dan LQ bernilai positif (+), berarti sektor tersebut merupakan spesialisasi kegiatan ekonomi di kabupaten/kota/kawasan.

c. RPr, RPs, dan LQ ketiganya bernilai negatif (-), berarti sektor tersebut kurang memiliki daya saing kompetitif maupun komparatif yang lebih unggul dibandingkan sektor yang sama pada tingkat provinsi.

\section{HASIL DAN PEMBAHASAN}

Demi kemudahan penyajian data hasil analisis, maka nama tiap-tiap sektor dan wilayah Administrasi di Pantura Jawa Barat disingkat dengan kode-kode pada tabel 1.

Tabel 1. Keterangan Singkatan Nama Wilayah dan Sektor Kajian

\begin{tabular}{ccc}
\hline Singkatan & Jenis & Keterangan \\
\hline KB & Wilayah Administrasi & Kabupaten Bekasi \\
KC & Wilayah Administrasi & Kabupaten Cirebon \\
KI & Wilayah Administrasi & Kabupaten Indramayu \\
KK & Wilayah Administrasi & Kabupaten Karawang \\
KS & Wilayah Administrasi & Kabupaten Subang \\
KoC & Wilayah Administrasi & Kota Cirebon \\
PKP & Sektor Ekonomi & Pertanian, Kehutanan, dan Perikanan \\
PP & Sektor Ekonomi & Pertambangan dan Penggalian \\
\hline
\end{tabular}

\section{Locational Quotient (LQ) dan Pengganda Basis (PB) di Pantura Jawa Barat}

Berdasarkan pengolahan data, diketahui bahwa Nilai LQ (Locational Quotient) pada sektor pertanian, kehutanan, dan perikanan (PKP) sebesar 0,77 (sektor non basis) serta sektor pertambangan dan penggalian (PP) sebesar 1,87 (sektor basis) selama tahun 2011 hingga 2015. Oleh karena itu, di kawasan Pantura Jawa Barat didapatkan bahwa sektor pertambangan dan penggalian yang menjadi sektor basis di kawasan Pantura Jawa Barat. Hasil selengkapnya disajikan pada tabel 2.

Tabel 2. Sektor Pertanian, Kehutanan, dan Perikanan (PKP) serta Sektor Pertambangan dan Penggalian (PP) di Kawasan Pantura Jawa Barat Tahun 2011 hingga 2015

\begin{tabular}{|c|c|c|c|c|c|c|c|c|c|c|}
\hline \multirow{2}{*}{ Sektor } & \multirow{2}{*}{ Tahun } & \multicolumn{6}{|c|}{ LQ Kawasan Pantura Jawa Barat } & \multirow{2}{*}{$\begin{array}{c}\text { Rataan } \\
\text { LQ }\end{array}$} & \multirow{2}{*}{$\begin{array}{c}\text { LQ } \\
\text { Kawasan }\end{array}$} & \multirow{2}{*}{ Notasi } \\
\hline & & KB & KC & KI & KK & KS & $\mathrm{KoC}$ & & & \\
\hline PKP & 2011 & 0,17 & 2,04 & 1,62 & 0,49 & 3,30 & 0,04 & 1,28 & 0,74 & - \\
\hline PP & 2011 & 0,87 & 0,58 & 5,19 & 1,35 & 5,73 & 0,00 & 2,29 & 1,80 & + \\
\hline PKP & 2012 & 0,17 & 2,12 & 1,75 & 0,48 & 3,54 & 0,04 & 1,35 & 0,75 & - \\
\hline $\mathrm{PP}$ & 2012 & 0,78 & 0,64 & 6,41 & 1,20 & 4,88 & 0,00 & 2,32 & 1,82 & + \\
\hline PKP & 2013 & 0,18 & 2,17 & 1,86 & 0,49 & 3,59 & 0,04 & 1,39 & 0,77 & - \\
\hline PP & 2013 & 0,63 & 0,71 & 7,14 & 1,27 & 5,22 & 0,00 & 2,50 & 1,86 & + \\
\hline PKP & 2014 & 0,17 & 2,18 & 1,93 & 0,49 & 3,69 & 0,04 & 1,42 & 0,78 & - \\
\hline PP & 2014 & 0,63 & 0,74 & 7,33 & 1,30 & 5,58 & 0,00 & 2,60 & 1,91 & + \\
\hline PKP & 2015 & 0,17 & 2,17 & 2,07 & 0,49 & 3,91 & 0,05 & 1,48 & 0,81 & - \\
\hline PP & 2015 & 0,64 & 0,77 & 7,85 & 1,30 & 5,62 & 0,00 & 2,70 & 1,98 & + \\
\hline \multicolumn{9}{|c|}{ Rata-Rata LQ Sektor PKP Kawasan Pantura Jawa Barat (Non Basis) } & 0,77 & - \\
\hline \multicolumn{9}{|c|}{ Rata-Rata LQ Sektor PP Kawasan Pantura Jawa Barat (Basis) } & 1,87 & + \\
\hline
\end{tabular}


Tabel 3. PB Sektor Pertanian, Kehutanan, dan Perikanan (PKP) serta Sektor Pertambangan dan Penggalian (PP) di Kawasan Pantura Jawa Barat Tahun 2011 hingga 2015

\begin{tabular}{|c|c|c|c|c|c|c|c|c|c|c|}
\hline \multirow{2}{*}{ Sektor } & \multirow{2}{*}{ Tahun } & \multicolumn{6}{|c|}{ PB Wilayah Kawasan Jawa Barat } & \multirow{2}{*}{$\begin{array}{c}\text { Rataan } \\
\text { PB }\end{array}$} & \multirow{2}{*}{$\begin{array}{c}\text { LQ } \\
\text { Kawasan }\end{array}$} & \multirow{2}{*}{$\begin{array}{c}\text { PB } \\
\text { Kawasan }\end{array}$} \\
\hline & & KB & KC & KI & KK & KS & KoC & & & \\
\hline PKP & 2011 & - & 5,44 & 6,84 & - & 3,37 & - & 5,22 & 0,74 & - \\
\hline PP & 2011 & - & - & 6,50 & 25,04 & 5,89 & - & 15,77 & 1,80 & 18,73 \\
\hline PKP & 2012 & - & 5,68 & 6,67 & - & 3,38 & - & 5,24 & 0,75 & - \\
\hline $\mathrm{PP}$ & 2012 & - & - & 5,91 & 32,63 & 7,97 & - & 15,50 & 1,82 & 21,51 \\
\hline PKP & 2013 & - & 5,80 & 6,38 & - & 3,35 & - & 5,18 & 0,77 & - \\
\hline $\mathrm{PP}$ & 2013 & - & - & 5,71 & 34,15 & 7,91 & - & 15,92 & 1,86 & 23,24 \\
\hline PKP & 2014 & - & 6,17 & 6,25 & - & 3,31 & - & 5,24 & 0,78 & - \\
\hline PP & 2014 & - & - & 5,61 & 35,26 & 7,46 & - & 16,11 & 1,91 & 24,03 \\
\hline PKP & 2015 & - & 6,71 & 6,19 & - & 3,22 & - & 5,37 & 0,81 & - \\
\hline PP & 2015 & - & - & 5,53 & 37,34 & 7,59 & - & 16,82 & 1,98 & 24,98 \\
\hline \multicolumn{10}{|c|}{ Rata-Rata PB Kawasan } & 22,50 \\
\hline
\end{tabular}

Berdasarkan tabel 2, diketahui bahwa sektor pertanian, kehutanan, dan perikanan yang menjadi sektor basis hanya berada di 3 wilayah, yaitu Kabupaten Cirebon $(2,13)$, Kabupaten Indramayu (1,84), dan Kabupaten Subang (3,60). Sedangkan, pada sektor pertambangan dan penggalian terlihat yang menjadi sektor basis, terjadi di 3 Kabupaten, yaitu Kabupaten Indramayu $(6,78)$, Kabupaten Karawang (1,28), dan Kabupaten Subang $(5,40)$. Selain itu, dari tabel 2 juga dapat diketahui bahwa wilayah dataran fluvial di Kabupaten Bekasi dan Kota Cirebon sudah tidak diorientasikan untuk kegiatan di sektor primer. Hal ini yang menyebabkan kedua sektor tersebut (PKP dan PP) sudah tidak menjadi sektor basis.

Guna mengetahui dampak pengganda basis sektor unggulan di kawasan Pantura Jawa Barat, digunakanllah analisis multiplier effect. Dari analisis ini, diketahui bahwa sektor pertanian, kehutanan, dan perikanan tidak mempunyai pengganda basis atau PB karena LQ wilayah tersebut terhadap Jawa Barat yang tidak terpenuhi. Sedangkan sektor pertambangan dan penggalian (PP) memilki nilai PB sebesar 22,50. Hal ini berarti setiap perubahan 1 angka pada sektor PP akan mengakibatkan perubahan pada sektor non basis sebesar 22,50 kali. Hasil selengkapnya mengenai pengganda basis di kawasan Pantura Jawa Barat tersaji pada tabel 3.

Berdasarkan tabel tersebut pula, diketahui bahwa Kabupaten Karawang memiliki pengganda basis sebesar 33,8 dengan laju perubahan sebesar 12,3 dari tahun 2011 hingga 2015 pada sektor pertambangan dan penggalian, angka ini menunjukan bahwa sektor tersebut merupakan sektor unggulan. Bahkan laju perubahan nilai PB di Kabupaten Karawang diatas PB kawasan Pantura Jawa Barat yang memiliki nilai sebesar 6,25.

\section{Model Rasio Pertumbuhan (MRP) di Pantura Jawa Barat}

Melalui analisis model rasio pertumbuhan, diketahui bahwa sektor pertambangan dan penggalian (pp) memiliki pertumbuhan yang rendah di tingkat provinsi, tetapi mempunyai pertumbuhan yang tinggi di tingkat kawasan Panturan Jawa Barat. Sedangkan sektor pertanian, kehutanan, dan perikanan memiliki pertumbuhan yang rendah baik di Pantura Jawa Barat maupun Provinsi Jawa Barat. Hasil selengkapnya mengenai model rasio pertumbuhan di Pantura Jawa Barat dan Provinsi Jawa Barat tersaji pada tabel 4 dan 5. 
Tabel 4. RPs Sektor Pertanian, Kehutanan, dan Perikanan (PKP) serta Sektor Pertambangan dan Penggalian (PP) di Kawasan Pantura Jawa Barat Tahun 2011 hingga 2015

\begin{tabular}{cccccccccccccc}
\hline \multirow{2}{*}{ Sektor } & \multicolumn{8}{c}{ RPs dan Notasi Kawasan Pantura Jawa Barat Tahun 2011 s.d. 2015} \\
\cline { 2 - 12 } & KB & Not. & KC & Not. & KI & Not. & KK & Not. & KS & Not. & KoC & Not. \\
\hline PKP & $-1,78$ & - & $-0,21$ & - & 2,00 & + & 0,00 & - & 0,87 & - & 0,40 & - \\
PP & 6,35 & + & $-1,82$ & - & $-3,09$ & - & 2,85 & + & 3,90 & + & 0,00 & + \\
\hline
\end{tabular}

Tabel 5. MRP Sektor Pertanian, Kehutanan, dan Perikanan (PKP) serta Sektor Pertambangan dan Penggalian (PP) di Kawasan Pantura Jawa Barat Tahun 2011 hingga 2015

\begin{tabular}{ccccc}
\hline \multirow{2}{*}{ Sektor } & \multicolumn{2}{c}{ RPs Pantura Jawa Barat } & \multicolumn{2}{c}{ RPr Provinsi Jawa Barat } \\
\cline { 2 - 5 } & Nilai & Notasi & Nilai & Notasi \\
\hline PKP & 0,58 & - & 0,14 & - \\
PP & 1,41 & + & $-0,15$ & - \\
\hline
\end{tabular}

\section{Analisis Overlay di Pantura Jawa Barat}

Analisis overlay menggunakan LQ rata-rata sebagai kriteria kontribusi selama periode 2011 hingga 2015. Sedangkan untuk kriteria pertumbuhan menggunakan analisis MRP, tepatnya menggunakan nilai RPs rata-rata selama periode 2011 hingga 2015 di Pantura Jawa Barat.

Tabel 6. Hasil Analisis Overlay Sektor Pertanian, Kehutanan, dan Perikanan (PKP) serta Sektor Pertambangan dan Penggalian (PP) di Kawasan Pantura Jawa Barat Tahun 2011 hingga 2015

\begin{tabular}{cccccccc}
\hline \multirow{2}{*}{ Sektor } & \multicolumn{2}{c}{$\begin{array}{c}\text { RPs Pantura } \\
\text { Jawa Barat }\end{array}$} & \multicolumn{2}{c}{$\begin{array}{c}\text { RPr Provinsi } \\
\text { Jawa Barat }\end{array}$} & \multicolumn{2}{c}{$\begin{array}{c}\text { LQ Pantura } \\
\text { Jawa Barat }\end{array}$} & $\begin{array}{c}\text { Hasil } \\
\text { Overlay }\end{array}$ \\
\cline { 2 - 7 } & Nilai & Notasi & Nilai & Notasi & Nilai & Notasi & \\
\hline PKP & 0,58 & - & 0,14 & - & 0,77 & - & -- \\
PP & 1,41 & + & $-0,15$ & - & 1,87 & + & +-+ \\
\hline
\end{tabular}

Berdasarkan analisis ini, diketahui bahwa sektor pertanian, kehutanan, dan perikanan di Kawasan Pantura Jawa Barat kurang memiliki daya saing kompetitif maupun komparatif yang lebih unggul dibandingkan dengan sektor yang sama di Provinsi Jawa Barat. Sementara itu, sektor pertambangan dan penggalian merupakan spesialisasi kegiatan ekonomi di kawasan Pantura Jawa Barat. Dari analisis ini pula terlihat bahwa sektor yang langsung bertumpu pada pemanfataan sumber daya alam di kawasan Pantura Jawa Barat belum memliki daya saing kompetitif maupun komparatif yang lebih unggul dibanding sektor yang sama di tingkat Provinsi Jawa Barat. Hal ini menunjukan bahwa optimalisasi pemanfaatan sumber daya alam baik terrestrial dan akuatis di Pantura Jawa Barat masih belum optimal dan hanya unggul pada sektor pertambangan dan penggalian.

\section{E. PENUTUP}

Hasil penelitian ini menunjukan bahwa sektor basis yang bertumpu secara langsung dengan sumber daya alam baik terrestrial dan akuatis di kawasan Pantura Jawa Barat bertumpu pada sektor pertambangan dan penggalian selama periode 2011 hingga 2015. Sektor ini memiliki pengganda basis 22,50. Selain itu, berdasarkan analisis model rasio pertumbuhan juga diketahui bahwa sektor pertambangan dan penggalian di kawasan Pantura Jawa Barat memilki pertumbuhan yang melebihi pertumbuhan sektor yang sama di Provinsi Jawa Barat. Akhirnya, semua model analisis tersebut disatukan dalam bentuk analisis overlay yang menujukan bahwa sektor pertambangan dan 
penggalian di Pantura Jawa Barat memiliki potensi daya saing yang unggul di Provinsi Jawa Barat. Diharapkan melalui penelitian ini mampu meningkatkan marwah dan upaya pembangunan ekonomi yang bertumpu pada sektor-sektor unggulan, khususnya yang berbasis pada optimalisasi pemanfataan sumber daya alam baik di tingkat regional maupun nasional dapat berjalan dengan baik dan berkelanjutan.

\section{F. DAFTAR PUSTAKA}

Badan Pusat Statistik [BPS]. (2015). Produk Domestik Bruto Indonesia Triwulanan 2011-2015. Jakarta: BPS.

Badan Pusat Statistik Kabupaten Bekasi [BPS Kab. Bekasi]. (2016). Produk Domestik Regional Bruto Kabupaten Bekasi menurut Lapangan Usaha 2011-2015. Bekasi: BPS Kab. Bekasi.

Badan Pusat Statistik Kabupaten Cirebon [BPS Kab. Cirebon]. (2016). Produk Domestik Regional Bruto Kabupaten Cirebon menurut Lapangan Usaha 2011-2015. Sumber: BPS Kab. Cirebon.

Badan Pusat Statistik Kota Cirebon [BPS Kota Cirebon]. (2016). Produk Domestik Regional Bruto Kota Cirebon menurut Lapangan Usaha 2011-2015. Cirebon: BPS Kota Cirebon.

Badan Pusat Statistik Kabupaten Indramayu [BPS Kab. Indramayu]. (2016). Produk Domestik Regional Bruto Kabupaten Indramayu menurut Lapangan Usaha 2011-2015. Indramayu BPS Kab. Indramayu.

Badan Pusat Statistik Provinsi Jawa Barat [BPS Jawa Barat]. (2016). Produk Domestik Regional Bruto Provinsi Jawa Barat menurut Lapangan Usaha 2011-2015. Bandung: BPS Prov. Jabar.

Badan Pusat Statistik Kabupaten Karawang [BPS Kab. Cirebon]. (2016). Produk Domestik Regional Bruto Kabupaten Karawang menurut Lapangan Usaha 2011-2015. Karawang: BPS Kab. Cirebon.

Badan Pusat Statistik Kabupaten Subang [BPS Kab. Cirebon]. (2016). Produk Domestik Regional Bruto Kabupaten Subang menurut Lapangan Usaha 2011-2015. Sumber: BPS Kab. Subang.

David. (2011). Top Resource-Rich Countries with Exposure to Emerging Markets. Tersedia [dalam jaringan] http://topforeignstocks.com/2011/07/30/top-resource-rich-countries-with-exposureto-emerging-markets/. Diakses 4 Desember 2016.

Gantara, W. P. dan T. Achmadi. (2012). "Model Pengembangan Wilayah Untuk Pembangunan Pelabuhan: Studi Kasus Pantai Selatan Jawa Timur". Jurnal Teknik Pomits (Publikasi Ilmiah Online Mahasiswa ITS), Vol. 1, No. 1, hlm. 1-6.

Kementerian Koordinator Bidang Perekonomian Republik Indonesia. (2013). DKI Jakarta, Jawa Timur, dan Jawa Barat Penyumbang Terbesar PDB Kuartal IV-2013. Tersedia [dalam jaringan] https://www.ekon.go.id/berita/view/dki-jakarta-jawa-timur-dan.516.html. Diakses 4 Desember 2016.

Lloyd, P. E. dan P. Dicksen. (1990). Location in Space (Theoretical Perspectives in Economic Geography). New York: Harper \& Row.

Manacika, I. K. (2010). Dampak Pariwisata Terhadap Permintaan Output Sektor Pertanian di Provinsi Bali. Tesis Program Pasca Sarjana, Universitas Udayana.

Mankiw, N. G. (2012). Essentials of Economic. Mason: Cengage Learning.

Muta'ali, L. (2015). Teknik Analisis Regional. Yogyakarta: Badan Penerbit Fakultas Geografi UGM.

Nisa, H. (2014). Analisis Potensi dan Pengembangan Wilayah Kabupaten Lebak Provinsi Banten. Skripsi Fakultas Ekonomi dan Bisnis, Universitas Diponegoro.

Pemerintah Provinsi Jawa Barat [Pemprov Jawa Barat]. (2013). Rencana Pembangunan Jangka Menengah Daerah Provinsi Jawa Barat. Bandung: Bappeda Jabar.

Putra, A. N. (2013). Analisis Potensi Ekonomi Kabupaten dan Kota Di Provinsi Daerah Istimewa Yogyakarta. Skripsi Fakultas Ekonomi dan Bisnis, Universitas Islam Negeri Syarif Hidayatullah.

Raven, P. H., D. M. Hassenzahl, dan L. R. Berg. (2013). Environment. New York: Jhon Wiley and Sons. 
S\&P Global Division. (2011). S\&P Global BMI, S\&P/IFCI Methodology. New York: S\&P Dow Jones Indices LLC.

Sabar, W. (2015). "Sektor Potensial Pengembangan Ekonomi Wilayah". Jurnal EcceS (Economics, Social, and Development Studies), Vol 2 (1), hlm. 48-61.

Sauter, M. B., C. B. Stockdale, dan P. Ausick. (2012). The World's Most Resource-Rich Countries. Tersedia [dalam jaringan] http://247wallst.com/special-report/2012/ 04/18/the-worlds-mostresource-rich-countries/. Diakses 4 Desember 2016.

Sukma, A. F. (2015). "Efek Pengganda Infrastruktur Pekerjaan Umum dalam Perekonomian Provinsi Bali”. Jurnal Perencanaan Wilayah dan Kota, vol. 26, no. 2, hlm. 100-110, Agustus 2015. DOI: 10.5614/jpwk.2015.26.2.3

Sultani, A. M. (2016). "Pengembangan Wilayah Berbasis Pendekatan Sosial Ekonomi di Kabupaten Barru Provinsi Sulawesi Selatan”. Jurnal Planomadani, vol. 5 (1) 2016. ISSN 2301 - 878X.

Syahrullah, D. (2012). Analisis pengaruh Produk Domestik Regional Bruto (PDRB), Pendidikan, dan Pengangguran terhadap Kemiskinan di Provinsi Banten Tahun 2009-2012. Skripsi Fakultas Ekonomi dan Bisnis.

Tarigan, R. (2015). Ekonomi Regional: Teori dan Aplikasi. Jakarta: Bumi Aksara. 